Annuaire du Collège de France 2017-2018

\title{
Histoire moderne et contemporaine du politique
}

\section{Pierre Rosanvallon}

\section{OpenEdition}

Journals

Édition électronique

URL : https://journals.openedition.org/annuaire-cdf/15673

DOI : $10.4000 /$ annuaire-cdf. 15673

ISBN : 978-2-7226-0572-5

ISSN : 2109-9227

Éditeur

Collège de France

Édition imprimée

Date de publication : 30 décembre 2020

Pagination : 471-473

ISBN : 978-2-7226-0516-9

ISSN : 0069-5580

Référence électronique

Pierre Rosanvallon, «Histoire moderne et contemporaine du politique », L'annuaire du Collège de France [En ligne], 118 | 2020, mis en ligne le 01 avril 2021, consulté le 22 août 2022. URL : http://

journals.openedition.org/annuaire-cdf/15673 ; DOI : https://doi.org/10.4000/annuaire-cdf.15673 


\title{
HISTOIRE MODERNE ET CONTEMPORAINE DU POLITIQUE
}

\author{
Pierre ROSANVALLON \\ Professeur au Collège de France
}

Mots-clés : histoire moderne, histoire contemporaine, histoire intellectuelle, histoire politique, démocratie

La série de cours «Les années 1968-2018 : une histoire intellectuelle et politique (II) 》 est disponible en audio et/ou en vidéo, sur le site internet du Collège de France (https://www.college-de-france.fr/site/pierre-rosanvallon/course-2017-2018.htm) ainsi que le colloque «La démocratie à l'âge de la post-vérité » (https://www.college-defrance.fr/site/pierre-rosanvallon/symposium-2017-2018.htm).

\section{ENSEIGNEMENT}

COURS - LES ANNÉES 1968-2018 : UNE HISTOIRE INTELLECTUELLE ET POLITIQUE (II)

Le cours 2017-2018 a été donné sous la forme de dix conférences ayant pour titre «1968-2018, une histoire intellectuelle et politique». Il a été reproduit dans les troisième et quatrième parties de l'ouvrage Notre histoire intellectuelle et politique (1968-2018) publié en août 2018 aux éditions du Seuil. Quatre autres cours ont été donnés dans les universités de Nantes, Grenoble, Duke University (États-Unis) et à la Central European University (Budapest).

\section{COLLOQUE - LA DÉMOCRATIE À L'ÂGE DE LA POST-VÉRITÉ}

Le séminaire a été donné sous la forme d'un colloque organisé le 27 février 2018 autour du thème «La démocratie à l'âge de la post-vérité ». Il aurait aussi pu s'intituler «Le cauchemar de Condorcet ». Les philosophes des Lumières avaient en effet parié que le développement de l'instruction permettrait de construire une démocratie de citoyens informés capables de délibérer rationnellement en vue du bien commun. Mais le cours des choses s'est révélé plus complexe, d'abord parce qu'ils avaient négligé le rôle toujours renaissant des passions et des émotions en 
politique, mais, plus encore, parce qu'ils n'avaient pas imaginé qu'une instruction de masse puisse conduire au relativisme destructeur que nous voyons aujourd'hui partout triompher, faisant système avec le développement des visions complotistes du monde, l'emprise croissante des marchands de doute et la dissolution des notions même de réalité et de vérité. Le colloque s'est proposé un double objectif sur la base de ce constat. Il s'est tout d'abord agi de poser clairement les termes du problème dans un premier temps, en en rappelant la constitution historique et en établissant les termes de sa conceptualisation philosophique. Une attention particulière a aussi été portée à la manière dont le développement d'Internet et des réseaux sociaux a radicalisé la question. Le colloque s'est penché, dans un second temps, à partir d'exemples et d'expériences, sur les conditions dans lesquelles il est aujourd'hui possible de retrouver le sens d'une rationalité et d'une approche des faits mieux partagées.

Le programme du colloque a été organisé au regard de ces questions.

\section{Position du problème}

- Pierre Rosanvallon (professeur au Collège de France) et Juliette Roussin (maître de conférences au Collège de France) : «Démocratie, raison et opinion »; - Dominique CARDON (professeur de sociologie à Sciences Po/Médialab) et Romain BADOUARD (maître de conférences à l'université de Cergy-Pontoise) : "Comment Internet a bouleversé les régimes de construction des opinions?».

\section{Comment inverser la tendance?}

- Gérald BRONNER (professeur à l'université Paris-Diderot) et Emmanuelle DAVIET (journaliste à France Inter, responsable du programme Interclass') : "Comment enseigner et éduquer à l'âge de la post-vérité ? ».

- Alain FISCHER (professeur au Collège de France, directeur de l'institut Imagine à l'hôpital Necker) et Serge HAROCHE (professeur émérite au Collège de France) :

«La science confrontée au relativisme».

\section{Publications}

\section{Ouvrages}

RoSANVALLON P., Notre histoire intellectuelle et politique (1968-2018), Paris, Seuil, coll. » Les livres du nouveau monde », 2018.

RosanVallon P., Refonder la démocratie pour le bien public, Toulouse, Privat, 2018.

\section{Traductions}

RosanVallon P., Dobre Rzady, traduction polonaise de Le Bon gouvernement par Grazyna Majcher, Varsovie, éditions Dialog, 2018.

Rosanvallon P., The Good Government. Democracy beyond Elections, traduction anglaise de Le Bon gouvernement par Malcolm Debevoise, Cambridge (Mass.), Harvard University Press, 2018.

Rosanvallon P., Pensare il populismo, traduction italienne sous la forme de livre de l'essai «Penser le populisme », paru dans laviedesidees.fr le 27 septembre 2011, Rome, éditions Castelvecchi, 2017. 
Rosanvallon P., traduction japonaise de La Contre-démocratie, Tokyo, Iwanami Shoten Publishers, 2017.

Rosanvallon P., Die Gegen-Demokratie. Politik in Zeitalter des Misstrauens, traduction allemande de La Contre-démocratie par Michael Halfbrodt, Hambourg, Hamburger Edition, 2017.

Rosanvallon P., Die Gute Regierung, nouvelle édition allemande de Le Bon gouvernement, Berlin, Suhrkamp, 2018.

Rosanvallon P., Die Gesellschaft des Gleichen, nouvelle édition allemande de La Société des égaux, Berlin, Suhrkamp, 2017.

\section{Articles scientifiques}

Rosanvallon P., «L'indétermination démocratique », in E. GROSSMAN et F. HeIDENREICH (dir.), Konstellationen der Souveränität in Europa. Les Constellations de la souveraineté en Europe, Berlin, Lit Verlag, 2017, p. 111-126; également traduit en allemand dans la revue Zeitschrift für Politische Theorie, vol. 7, nº 1, 2016.

RosAnVALLON P., «Quale redistribuzione ? Le aporie della solidarietà », Vita e Pensiero, novembre-décembre 2017, p. 23-31.

RosAnVALlON P., «Populism and democracy in the twenty-first century », in M. IGNATIEFF et S. RocH, Rethinking Open Sciety. New adversaries and New Opportunities, Budapest, Central European University Press, 2018, p. 227-242.

Rosanvallon P., «Raconter la vie, premier bilan » (entretien), Revue de la Bibliothèque nationale de France, $\mathrm{n}^{\mathrm{O}}$ 52, 2016.

Rosanvallon P., «About the comments on Good Government», Philosophy and Public Issues, vol. 7, n 3, 2017, p. 97-109 (numéro spécial de la revue consacré à l'ouvrage Le Bon Gouvernement).

RosAnVALLON P., « Rendre visible la société, c'est donner une dignité à des personnes qu'on côtoie sans les voir », Horizons publics, n $^{\circ}$ 4, juillet-août 2018, p. 74-79. 
